\title{
Environmental and Engineering Geophysical University at SAGEEP 2008: Geophysical Instruction for Non-Geophysicists
}

\author{
Final Summary Report for \\ DOE Award DE-FG02-08ER64541 \\ In response to \\ DOE Office of Science Solicitation DE-PS02-08ER08-01 \\ DOE Funding: \$5,000
}

by

(on behalf of the Environmental and Engineering Geophysical Society)

Dr. Jeffrey G. Paine, Principal Investigator

Research Scientist

Bureau of Economic Geology

jeff.paine@beg.utexas.edu; (512) 471-1260

Dr. Gregory S. Baker, Co-Principal Investigator

Jones/Bibee Endowed Assoc. Professor of Geophysics

Dept. of Earth \& Planetary Sciences, University of Tennessee

mailto:gbaker@tennessee.edu; (865) 974-6003

Dr. William E. Doll, Co-Principal Investigator

Battelle

dollw@battelle.org; (865) 483-2548

March 2009 


\section{Summary}

The Environmental and Engineering Geophysical Society (EEGS), a nonprofit professional organization, conducted an educational series of seminars at the Symposium on the Application of Geophysics to Engineering and Environmental Problems (SAGEEP) in Philadelphia in April 2008. The purpose of these seminars, conducted under the name Environmental and Engineering Geophysical University (EEGU) over three days in parallel with the regular SAGEEP technical sessions, was to introduce nontraditional geophysical conference attendees to the appropriate use of geophysics in environmental and engineering projects. Five half-day, classroom-style sessions were led by recognized experts in the application of seismic, electrical, gravity, magnetics, and ground-penetrating radar methods. Classroom sessions were intended to educate regulators, environmental program managers, consultants, and students who are new to near-surface geophysics or are interested in learning how to incorporate appropriate geophysical approaches into characterization or remediation programs or evaluate the suitability of geophysical methods for general classes of environmental or engineering problems. EEGS received \$5,000 from DOE to support adding this new program element to the regular SAGEEP technical program. Funds were requested from DOE to support this new program and were intended to compensate instructors, partially support instructor travel to and from SAGEEP, promote the educational opportunity to nontraditional groups and organizations, and support instruction-related costs including space and equipment rental.

Three instructors presented material for the 2008 EEGU sessions in Philadelphia. On Monday, April 7, 2008, Phil Sirles (hydroGeophysics, Inc., Denver, Colorado) presented two introductory sessions on "What is Environmental and Engineering Geophysics" and "What Can Environmental and Engineering Geophysics Do for You?” On Tuesday, April 8, Dr. Gregory Baker (University of Tennessee) presented morning and afternoon sessions on "Geophysics for Water Resources and Contaminants." On Wednesday, April 9, William Owen (California Department of Transportation) and Mark Dunscomb (Schnabel Engineering) presented morning and afternoon sessions on "Geophysics for Engineering, Transportation, Hazards, and UXO Investigations." These sessions were offered to first-time SAGEEP attendees at discounted registration rates that were available for single-day or all three conference days. Attendance over the three days ranged from 15 to 25 per session.

Funds provided by the Department of Energy to partly support the EEGU sessions were used to produce a promotional brochure for distribution to the intended audience (regulators, teachers, students, and environmental program managers), provide small honoraria to instructors, produce classroom materials, support EEGS staff time to prepare and arrange the sessions, and provide for use of the classroom and audio/visual equipment. Rosters of attendance were maintained for each day. Comments and critiques were solicited from attendees at the end of each day. These comments were overwhelmingly positive, particularly for the Monday overview sessions and the Tuesday water- and contaminant-focused sessions. The popularity of the inaugural EEGU initiative has led to inclusion of it in the 2009 SAGEEP conference (Fort Worth, Texas) virtually unchanged. 